\title{
Higher milk intake increases fracture risk: confounding or true association?
}

\author{
S. Sahni ${ }^{1,2} \cdot$ S. S. Soedamah-Muthu ${ }^{3} \cdot$ C. M. Weaver ${ }^{4}$
}

Received: 8 February 2017 / Accepted: 10 May 2017 /Published online: 1 June 2017

(C) International Osteoporosis Foundation and National Osteoporosis Foundation 2017

Global shifts in aging and increased life expectancy puts demands on health systems. [1] As age-related chronic diseases, osteoporosis and low bone mass are major public health threats [2, 3]. Milk is a good source of bone-specific nutrients [calcium, vitamin D (when fortified), protein, magnesium, potassium, phosphorus]. Studies have reported beneficial associations between milk and bone mineral density [4-10]. However, data on mortality [11-15] and fracture risk are conflicting [14, 16-19], with studies reporting beneficial [13, 16], neutral [8, 11, 12, 15, 17-19], and adverse associations [14].

The largest study [14] on milk intake, fractures and mortality has contributed to controversies surrounding potential benefits of these foods for bone health and longevity. Michaelsson et al. [14] examined milk intake in two large Swedish cohorts. Primary outcomes included mortality, incident fracture, hip fracture over follow-up (women, 20.1 years; men, 11.2 years). In women, $\geq 3$ glasses of milk/day was associated with $93 \%$ increased risk of mortality compared with < 1 glass $(200 \mathrm{ml})$. For every glass of milk, fracture and hip fracture risk was $2-$

S. Sahni

ShivaniSahni@hsl.harvard.edu

1 Institute for Aging Research, Hebrew SeniorLife, 1200 Centre St, Boston, MA 02131, USA

2 Department of Medicine, Beth Israel Deaconess Medical Center, Harvard Medical School, 330 Brookline Ave, Boston, MA 02215, USA

3 Division of Human Nutrition, Wageningen University, HELIX, Building 124, room 1063, Stippeneng 4, WE 6708 Wageningen, The Netherlands

4 Department of Nutrition Science, Purdue University, STON 214, 700 W. State Street, West Lafayette, IN 2059, USA
$9 \%$ higher in women. Cheese and fermented milk showed a $10-15 \%$ lower fracture and mortality risk in women. Overall, $\geq 3$ glasses of milk/day was associated with higher mortality in adults and with higher fracture incidence in women. The biological rational included high levels of D-galactose in milk (also found in cheese and fermented milk), which increases oxidative stress and chronic low grade inflammation in animal models. This mechanism is unsubstantiated by other studies.

This study has raised several issues. The highest relative risks were in women with high milk intake (9\% of the population). These women, aged $>50$ when the study started were followed for 20 years. At age 70, people are likely to die from multiple causes and not due to milk intake perse. These women were at increased risk of comorbidities, prone to dietary changes pursuant to age, loss of spouse, and changes in living arrangement. Furthermore, baseline vitamin D status was missing, and Charlson's comorbidity index does not account for diabetes, hypertension, or hypercholesterolemia separately. The high risk associations became weaker if only baseline (compared to two repeated measures) milk intake was associated with mortality risk. The FFQ had limited food items and was not validated for milk. The conclusion disagrees with a recent meta-analysis of 29 prospective cohort studies on milk and mortality that found no association [15].

Large cohort studies provide valuable information on dietdisease relationships. However, the question about true associations or confounded results cannot yet be answered. Validated measurements should be utilized, and a detailed assessment of confounders including vitamin D status are necessary to answer important questions related to milk intake and its effect on fracture and mortality. Large intervention studies of other under-studied dairy foods (yogurt and cheese) would clarify nutritional equivalency of dairy foods in order to optimize bone health. An emerging area of fermented dairy foods, microbiome and aging, could provide valuable insights 
into the unexplored mechanisms via which dairy foods may affect aging in general and skeletal aging in particular.

\section{Compliance with ethical standards}

Conflict of interest Dr. Sahni has received institutional grants from General Mills Bell Institute of Health and Nutrition, Policy Analysis Inc./Amgen and Dairy Management Inc. Dr. Sahni serves as a member of the National Dairy Council's Nutrition Research Scientific Advisory Committee.

Dr. Weaver is a scientific adviser to Pharmavite, Pfizer, and Yogurt In Nutrition, Danone Institute International. Dr. Soedamah-Muthu received funding from the Global Dairy Platform, Dairy Research Institute and Dairy Australia for a meta-analysis on cheese and blood lipids (2012) and a meta-analysis of dairy and mortality (2015). She has received an international i.e. The Wiebe Visser International Dairy Nutrition Prize from the Dutch Dairy Association's (NZO) Utrecht Group.

\section{References}

1. Mortality GBD, Causes of Death C (2016) Global, regional, and national life expectancy, all-cause mortality, and cause-specific mortality for 249 causes of death, 1980-2015: a systematic analysis for the Global Burden of Disease Study 2015. Lancet 388(10053): $1459-1544$

2. Wright NC, Looker AC, Saag KG, Curtis JR, Delzell ES, Randall $\mathrm{S}$, Dawson-Hughes B (2014) The recent prevalence of osteoporosis and low bone mass in the United States based on bone mineral density at the femoral neck or lumbar spine, 2520. J Bone Miner Res 29(11):-6

3. Hernlund E, Svedbom A, Ivergard M, Compston J, Cooper C, Stenmark J, McCloskey EV, Jonsson B, Kanis JA (2013) Osteoporosis in the European Union: medical management, epidemiology and economic burden. A report prepared in collaboration with the International Osteoporosis Foundation (IOF) and the European Federation of Pharmaceutical Industry Associations (EFPIA). Arch Osteoporos 8:136

4. Thorpe MP, Jacobson EH, Layman DK, He X, Kris-Etherton PM, Evans EM (2008) A diet high in protein, dairy, and calcium attenuates bone loss over twelve months of weight loss and maintenance relative to a conventional high-carbohydrate diet in adults. J Nutr Jun 138(6):1096-1100

5. Moschonis G, Manios Y (2006) Skeletal site-dependent response of bone mineral density and quantitative ultrasound parameters following a 12-month dietary intervention using dairy products fortified with calcium and vitamin D: the Postmenopausal Health Study. Br J Nutr Dec 96(6):1140-1148

6. McCabe LD, Martin BR, McCabe GP, Johnston CC, Weaver CM, Peacock M (2004) Dairy intakes affect bone density in the elderly. Am J Clin Nutr 80(4):1066-1074

7. Sato Y, Iki M, Fujita Y, Tamaki J, Kouda K, Yura A, Moon JS, Winzenrieth R, Iwaki H, Ishizuka R, Amano N, Tomioka K, Okamoto N, Kurumatani N (2015) Greater milk intake is associated with lower bone turnover, higher bone density, and higher bone microarchitecture index in a population of elderly Japanese men with relatively low dietary calcium intake: Fujiwara-kyo Osteoporosis Risk in Men (FORMEN) Study. Osteoporos Int 26(5):1585-1594

8. Sahni S, Tucker KL, Kiel DP, Quach L, Casey VA, Hannan MT (2013) Milk and yogurt consumption are linked with higher bone mineral density but not with hip fracture: the Framingham Offspring Study. Arch Osteoporos 8(1-2):119

9. Sahni S, Mangano KM, Kiel DP, Tucker KL, Hannan MT (2017) Dairy intake is protective against bone loss in older vitamin D supplement users: the Framingham Study. J Nutr. doi:10.3945/jn. 116.240390

10. Prince R, Devine A, Dick I, Criddle A, Kerr D, Kent N, Price R, Randell A (1995) The effects of calcium supplementation (milk powder or tablets) and exercise on bone density in postmenopausal women. J Bone Miner Res 10(7):1068-1075

11. Thorning TK, Raben A, Tholstrup T, Soedamah-Muthu SS, Givens I, Astrup A (2016) Milk and dairy products: good or bad for human health? An assessment of the totality of scientific evidence. Food Nutr Res 60:32527

12. Soedamah-Muthu SS, Ding EL, Al-Delaimy WK, Hu FB, Engberink MF, Willett WC, Geleijnse JM (2011) Milk and dairy consumption and incidence of cardiovascular diseases and allcause mortality: dose-response meta-analysis of prospective cohort studies. Am J Clin Nutr 93(1):158-171

13. Talaei M, Koh WP, Yuan JM, Pan A (2016) The association between dairy product intake and cardiovascular disease mortality in Chinese adults. Eur J Nutr. Jul 22.

14. Michaelsson K, Wolk A, Langenskiold S, Basu S, Warensjo Lemming E, Melhus H, Byberg L (2014) Milk intake and risk of mortality and fractures in women and men: cohort studies. BMJ 349:g6015

15. Guo J, Astrup A, Lovegrove JA, Gijsbers L, Givens DI, SoedamahMuthu SS (2017) Milk and dairy consumption and risk of cardiovascular diseases and all-cause mortality: dose-response metaanalysis of prospective cohort studies. European Journal of Epidemiology.

16. Sahni S, Mangano KM, Tucker KL, Kiel DP, Casey VA, Hannan MT (2014) Protective association of milk intake on the risk of hip fracture: results from the Framingham original cohort. J Bone Miner Res 29(8):1756-1762

17. Bischoff-Ferrari HA, Dawson-Hughes B, Baron JA, Kanis JA, Orav EJ, Staehelin HB, Kiel DP, Burckhardt P, Henschkowski J, Spiegelman D, Li R, Wong JB, Feskanich D, Willett WC (2011) Milk intake and risk of hip fracture in men and women: a metaanalysis of prospective cohort studies. J Bone Miner Res 26(4): 833-839

18. Feskanich D, Bischoff-Ferrari HA, Frazier AL, Willett WC (2014) Milk consumption during teenage years and risk of hip fractures in older adults. JAMA Pediatr 168(1):54-60

19. Kanis JA, Johansson H, Oden A, De Laet C, Johnell O, Eisman JA, Mc Closkey E, Mellstrom D, Pols H, Reeve J, Silman A, Tenenhouse A (2005) A meta-analysis of milk intake and fracture risk: low utility for case finding. Osteoporos Int 16(7):799-804 